This is a self-archived version of an original article. This version may differ from the original in pagination and typographic details.

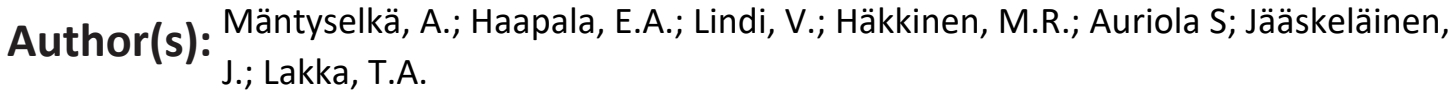

Title: Associations of IGF-1 and Adrenal Androgens with Cognition in Childhood

Year: 2019

Version: Accepted version (Final draft)

Copyright: (c) 2019 S. Karger AG, Basel.

Rights: In Copyright

Rights url: http://rightsstatements.org/page//nC/1.0/?language=en

Please cite the original version:

Mäntyselkä, A., Haapala, E.A., Lindi, V., Häkkinen, M.R., Auriola S, Jääskeläinen, J., Lakka, T.A. (2019). Associations of IGF-1 and Adrenal Androgens with Cognition in Childhood. Hormone Research in Paediatrics, 91(5), 329-335. https://doi.org/10.1159/000501719 


\section{Associations of IGF-1 and adrenal androgens with cognition in childhood}

Mäntyselkä Aino*1, Haapala Eero $\mathrm{A}^{2,3}$, Lindi Virpi ${ }^{2,4}$, Häkkinen Merja $\mathrm{R}^{5}$, Auriola Seppo ${ }^{5}$, Jääskeläinen Jarmo ${ }^{1}$, Lakka Timo $A^{2,6,7}$

${ }^{1}$ Department of Pediatrics, School of Medicine, Kuopio University Hospital, and University of Eastern Finland, Kuopio, Finland; ${ }^{2}$ Institute of Biomedicine, School of Medicine, University of Eastern Finland, Kuopio, Finland; ${ }^{3}$ Faculty of Sport and Health Sciences, University of Jyväskylä, Jyväskylä, Finland; ${ }^{4}$ University of Eastern Finland Library, Kuopio, Finland; ${ }^{5}$ School of Pharmacy, University of Eastern Finland, Kuopio, Finland; ${ }^{6}$ Department of Clinical Physiology and Nuclear Medicine, School of Medicine, University of Eastern Finland and Kuopio University Hospital, Kuopio, Finland and ${ }^{7}$ Kuopio Research Institute of Exercise Medicine, Kuopio, Finland

Short title: Associations of IGF-1 and adrenal androgens with cognition

*Corresponding author

Aino Mäntyselkä

Department of Pediatrics

Kuopio University Hospital and University of Eastern Finland

Puijonlaaksontie 2, 70210 Kuopio

P.O. Box 100, Fl-70029 Kuopio Finland

Phone: +358-50-3716869; Fax: +358-17-172410

E-mail: aino.mantyselka@kuh.fi

Keywords: DHEAS, Insulin-like growth factor-1, adrenarche, cognition 


\section{Abstract}

Background: Little is known about the association between adrenarche and cognition in general populations of children. We therefore studied the associations of dehydroepiandrosterone sulfate (DHEAS), androstenedione (A4), testosterone, insulin-like growth factor (IGF-1), and adrenarche with cognition among prepubertal children.

Methods: These cross-sectional analyses are based on baseline data of the Physical Activity and Nutrition in Children Study. A total of 387 children (183 girls, 204 boys) were included in the analyses. The Raven`s Coloured Progressive Matrices (CPM) score was used to assess non-verbal reasoning. Serum adrenal androgens and IGF-1 concentrations were measured and clinical signs of androgen action were evaluated.

Results: Higher IGF- 1 among boys ( $\beta=0.149, P=0.033$ ) was related to a better Raven's CPM score after adjustment for age and parental education. Adrenal androgens in girls or boys or IGF-1 in girls were not associated with the score. There were no differences in Raven's CPM score between children with biochemical adrenarche (DHEAS $\geq 40 \mu \mathrm{g} / \mathrm{dL}$ ) or with clinical signs of androgen action and children without them.

Conclusion: The results suggest that higher serum IGF-1 among boys is related to better cognition in prepubertal children. We could not provide evidence for the associations of adrenal maturation with cognition in prepubertal children. 


\section{Introduction}

Dehydroepiandrosterone (DHEA) and its sulfate (DHEAS) are abundant steroid hormones and androgen precursors produced by adrenal cortex. DHEAS has been suggested as an important neurosteroid that promotes neuroneogenesis, neuronal growth, and neuronal survival by its antioxidative, anti-inflammatory, and antiglucocorticoid effects $[1,2,3]$. Serum DHEAS levels have been positively correlated with global cognition, working memory, attention, and verbal fluency in some studies among adults [4,5]. However, studies on DHEA supplementation have failed to improve cognitive function in adults [1], except one study in young men who were treated with high doses of DHEA [6]. Moreover, DHEA treatment has not improved cognitive function in Addison`s disease patients $[7,8]$.

Adrenarche refers to an increase in the secretion of DHEA and DHEAS during maturation in midchildhood [9]. Adrenal maturation occurs at the same time as the growth in brain volume ceases [10] and the cortical brain maturation begins $[11,12]$. There are few studies on the association between DHEAS and cognition in children. There is some evidence that higher salivary DHEA levels are associated with better visual attention [13] and better working memory but lower performance in spatial working memory [14] in children and adolescents. However, prepubertal girls with premature adrenarche had no differences in cognitive measures such as intelligence quotient (IQ) and executive functioning compared to on-time girls [15]. It has also been suggested that an increased concentration of DHEA at around seven years of age enables maintaining synaptic plasticity $[16,3]$ with a prolonged development of the cortex, particularly in the insula, thalamus, and anterior cingulate [16], structures that integrate somatosensory, homeostatic, and emotional information $[17,18]$.

Major adrenocortical androgens are DHEA, DHEAS, and androstenedione (A4), whereas only a small portions of androstenedione are converted to testosterone [19]. Prepubertal children with premature adrenarche demonstrate also elevated serum insulin-like growth factor-1 (IGF-1) levels [20,21]. IGF-1 has been found to increase the production of adrenal androgens, such as DHEAS, in cultured human 
adrenocortical cells [22]. Increased circulating IGF-1 concentration has been associated with enhanced neurogenesis, learning, and memory [23]. Serum IGF-1 levels have been directly associated with an IQ in children aged 7-8 years [24]. Moreover, there is some evidence that a decrease in serum IGF-1 levels is associated with a decline in cognition among older adults [25].

Androgens may play an important role in cortical maturation and cognitive development during midchildhood $[10,11,12,3]$. However, little is known about the association between adrenarche and cognition in general populations of children. Therefore, we studied the associations of serum DHEAS, serum A4, serum testosterone, serum IGF-1, biochemical adrenarche, and clinical signs of androgen action with cognition among prepubertal children aged $6-8$ years. 


\section{Material and methods}

\subsection{Study design and population}

The present analyses are based on baseline data of the Physical Activity and Nutrition in Children (PANIC) Study which is a physical activity and dietary intervention study in a population sample of primary school children from the city of Kuopio in Finland (Clinical Trial Registration Number: NCT01803776) [26].

Altogether 736 children $6-8$ years of age from 16 schools of the city of Kuopio were invited to participate in the study. Of these children, $512(70 \%)$ participated in the baseline examinations in 2007-2009. The participants did not differ in age, sex distribution, or body mass index standard deviation score (BMI-SDS) from all children who started the first grade in the primary schools of Kuopio in 2007-2009 based on comprehensive data obtained from school health examinations.

The exclusion criteria for the present analyses were central puberty and any long-term medication that could have an effect on adrenal function. We also excluded one child who had a serious delay in cognitive function observed by a physician, 21 children who were born before gestational age $<37$ weeks, and 12 children with a birth weight standard deviation score (SDS) $\leq-2.0$. A total of 387 children (183 girls, 204 boys) had data on variables used and were included in the present analyses.

\subsection{Assessment of cognition}

Raven`s Coloured Progressive Matrices (CPM) was used to assess non-verbal reasoning [27]. One trained researcher administered the assessments. Raven`s CPM includes 36 large figures with a part missing. The children were asked to select a correct part that completes the figure from six alternatives presented beneath the large figure. Raven`s CPM requires the ability to find similarities, differences, and discrete patterns, does not depend on acquired knowledge or language skills[27], and has been suggested to represent all-core components of executive functions, such as inhibition and interference control, working memory, and cognitive flexibility [28]. The Raven`s CPM score was the number of 
correct answers, ranging from 0 to 36, a higher score indicating better cognition. A majority of children (87.3\%) performed the Raven's test between 12 am and 4 pm.

\subsection{Assessment of body size and pubertal signs}

Body weight was measured twice after an overnight fast, bladder emptied, and standing in light underwear by InBody ${ }^{\circledR 7} 720$ bioelectrical impedance device (Biospace Co. Ltd., Seoul, Southern Korea) to accuracy of $0.1 \mathrm{~kg}$. The mean of these two values was used in the analyses. Height was measured three times in the Frankfurt plane without shoes using a wall-mounted stadiometer to accuracy of 0.1 $\mathrm{cm}$. The mean of the two nearest values was used in the analyses. BMI was calculated as weight $(\mathrm{kg})$ divided by height $(\mathrm{m})$ squared. Height-SDS and BMI-SDS were calculated according to the Finnish growth references [29].

Central gonadotropin-dependent puberty was defined by a clinical examination as breast development at $\geq 2$ for girls and testicular volume $\geq 4 \mathrm{ml}$ assessed using an orchidometer for boys based on the 5-stage criteria described by Tanner [30]. Clinical signs of androgen action, including adult type body odor, oily hair, acne, comedones, and pubic or axillary hair, were evaluated by a specifically trained physician; body odor and oiliness of the hair were also assessed by asking about them from the parents.

\subsection{Assessment of IGF-1 and adrenal androgens}

Serum samples were taken after an overnight fast and were kept deep frozen until they were analyzed. Serum DHEAS concentrations were determined using an ELISA kit (Alpha Diagnostic International, San Antonio, TX, USA). The intra-assay coefficient of variation (CV) of the DHEAS method was $7.5-11.5 \%$ and the inter-assay CV was 7.0-11.0\%. Serum IGF-1 concentrations were determined using an ELISA kit (Mediagnost, Reutlingen, Germany). The intra-assay CV of the IGF-1 method was $5.1-6.6 \%$ and the inter-assay $\mathrm{CV}$ was $7.7-9.2 \%$. A4 and testosterone were determined by liquid chromatography-tandem mass spectrometry as previously reported [31]. 


\subsection{Assessment of parental education}

The parents were asked to report their highest completed or ongoing educational degree (vocational school or less, polytechnic, or university). The degree of the more educated parent was used in the analyses.

\subsection{Statistical methods}

The SPSS statistical analysis software, Version 24.0 (IBM Corp., Armonk, NY, USA), was used in the statistical analyses. We compared basic characteristics between girls and boys using the Student's $t$ test, the Mann-Whitney`s $U$ test, or the Chi-square test. The associations of IGF-1, DEHAS, A4 and testosterone with the Raven`s CPM score were investigated using the linear regression analysis adjusted for age, sex, and parental education in all children and adjusted for age and parental education in girls and boys separately. The associations of IGF-1 and adrenal androgens with the Raven`s CPM score were adjusted further for BMI-SDS in all analyses. We compared the Raven`s CPM score between children with higher serum DHEAS levels $\geq 1.08 \mu \mathrm{mol} / \mathrm{L}(\geq 40 \mu \mathrm{g} / \mathrm{dL})$, which has been suggested as the definition for biochemical adrenarche [32], and children with lower DHEAS levels $<1.08 \mu \mathrm{mol} / \mathrm{L}(<40 \mu \mathrm{g} / \mathrm{dL})$ using the general linear model adjusted for age, sex, and parental education in all children and adjusted for age and parental education in girls and boys separately. We used the general linear model to compare the Raven`s CPM score between children with clinical signs of adrenarche and children without them adjusted for age, sex, and parental education in all children and adjusted for age and parental education in girls and boys separately. There were only 10 children with premature adrenarche [DHEAS $\geq 1.08 \mu \mathrm{mol} / \mathrm{L}(\geq 40 \mu \mathrm{g} / \mathrm{dL})$ ] and clinical signs of androgen action in a girl aged $<8$ years or in a boy $<9 y e a r s]$ in our study population. Therefore, we did not compare the Raven`s CPM score between children with premature adrenarche and those without it. Associations with $P<0.05$ were considered statistically significant. 


\section{Results}

Boys were heavier and taller than girls at the age of 6-8 years and at birth (Table 1). Serum IGF-1 and testosterone were higher in girls than in boys, but serum DHEAS and A4 did not differ between sexes (Table 1).

Serum DHEAS, A4 or testosterone were not associated with the Raven`s CPM score in all children adjusted for age, sex, and parental education or in girls or boys adjusted for age and parental education (Table 2). Further adjustment for BMI-SDS did not change the result in all children, girls, or boys (Table 2).

Altogether 50 children ( 22 girls, 28 boys) had serum DHEAS $\geq 1.08 \mu \mathrm{mol} / \mathrm{L}(\geq 40 \mu \mathrm{g} / \mathrm{dL}$ ). The Raven`s CPM score did not differ between children with serum DHEAS $\geq 1.08 \mu \mathrm{mol} / \mathrm{L}$ [ $\geq 40 \mu \mathrm{g} / \mathrm{dL}$ (mean 25 , 95\% confidence interval (Cl) 23-24)] and children with serum DHEAS $<1.08 \mu \mathrm{mol} / \mathrm{L}[<40 \mu \mathrm{g} / \mathrm{dL}$ (mean $24,95 \% \mathrm{Cl} 24-26)]$ after adjustment for age, sex, and parental education in all children $(P=0.436)$. Neither did the Raven`s CPM score differ between these two groups in girls $(P=0.868)$ or boys $(P=$ 0.412) after adjustment for age and parental education.

Altogether 62 children (43 girls, 19 boys) had clinical signs of adrenarche. The Raven`s CPM score did not differ between children with clinical signs of adrenarche (mean $24,95 \% \mathrm{Cl} 24-25$ ) and children without them (mean $24,95 \% \mathrm{Cl} 23-25)$ after adjustment for age, sex, and parental education $(P=$ 0.818). Neither did the Raven`s CPM score differ between these two groups in girls $(P=0.574)$ or boys $(P=0.835)$ after adjustment for age and parental education.

Serum IGF-1 was not associated with the Raven`s CPM score in all children adjusted for age, sex, and parental education or in girls after adjustment for age and parental education (Table 2). However, higher serum IGF-1 was related to a better Raven`s CPM score in boys after adjustment for age and parental education $(\beta=0.149, P=0.033)$. The association between serum IGF-1 and the Raven`s CPM score in boys was even stronger after further adjustment for BMI-SDS ( $\beta=0.179, P=0.016$; Table 2$)$. 


\section{Discussion and conclusion}

We found that higher serum IGF-1 but not adrenal androgens were related to a better Raven`s CPM score among boys. Neither IGF-1 nor adrenal androgens were related to the Raven's CPM score in girls. Furthermore, there were no differences in the Raven's CPM score between children with adrenarche and those without it.

Our observations on the association between higher IGF-1 and better cognition in boys is in line with the results of a previous study suggesting a positive association between IGF- 1 and a verbal IQ in children aged 7-8 years [24]. Furthermore, increased serum IGF-1 concentration was related to improved executive functions measured by the Block design test and IQ in seven-year-old children undergoing a long-term growth hormone therapy [33].

An explanation for these findings may be that IGF-1 is widely expressed in the central nervous system and the growth hormone/IGF-1 axis is involved in brain growth, development, myelination, and plasticity [34,35]. IGF-1 has been found to increase the proliferation of progenitor cells and the formation of new neurons in hippocampus in experimental animal and in vitro studies $[34,36]$. Moreover, cerebral cortex has been suggested to be especially sensitive to the actions of IGF-1 [34]. IGF-1 could thereby improve learning and memory [23]. It has been suggested that the effects of IGF1 on cognition are mediated by brain-derived neurotrophic factor (BDNF) and vascular endothelial derived growth factor (VEGF) interacting with energy supply, estrogen, and corticosterone $[37,38]$. However, the exact mechanisms behind the association between the growth hormone/IGF-1 axis and various cognitive functions during growth and maturation are still unknown.

We found that a higher serum IGF-1 concentration was related to a better Raven `s CPM score among boys. Contrary to our results, the positive association between IGF-1 and cognition among children with a mean age of eight years in the Avon Longitudinal Study of Parents and Children (ALSPAC) study was stronger in girls than in boys. Children in the ALSPAC study were slightly older than children in our study. In addition puberty was not taken into account in the ALSPAC study. Puberty may represent a 
reorganizational period to the brain $[39,40]$. Boys reach peak cortical thickness in the frontal area, which is involved in planning, organizing, and executive functions, approximately one year later than girls [41], at 12 years in boys and at 11 years in girls. Similarly, grey matter volume in parietal cortex reaches its peak volume about 1.5 years later in boys than in girls [41]. Serum IGF-1 was higher in girls than in boys in the present study among prepubertal children which is in line with the observations of previous studies [42,43]. Because IGF-1 stimulates cellular proliferation in the development of central nervous system [34,35], it is possible that boys with higher IGF-1 have more advanced brain maturation and better cognitive abilities than other boys.

The results of the ALSPAC study suggest that the link between IGF-1 and IQ in children, particularly in girls, is largely explained by parental education and socioeconomic position [24]. However, in the present study higher IGF-1 was related to better cognition in boys even after adjustment for parental education. These partly contrasting findings may be due to a more homogenous childhood environment in Finland than in the United Kingdom.

Increased circulating DHEAS levels have been linked to improved brain plasticity during growth and maturation $[16,3]$. Some earlier studies have found a positive association between salivary DHEA levels measured before a cognitive task and working memory in young women [44]. Higher DHEA levels in saliva have also been associated with better visual attention [13] and better working memory but lower performance in spatial working memory tasks in children and adolescents [14]. Moreover, higher serum DHEAS levels were associated with better executive function and working memory in women aged 18-75 years [4]. However, we observed no association between DHEAS and cognition in girls or boys. This is in line with the observation of a previous study among 129 children five years of age that there was no correlation between DHEA in saliva and cognition [45]. The reason for not finding an association between DHEAS and cognition may be that we studied younger individuals and used different measures of cognition than other studies $[4,44,13]$. DHEAS may be a more important factor for performance in specific attention and working memory tasks [6] than in non-verbal reasoning tasks, such as Raven's CPM. Higher DHEA or DHEA/cortisol ratio has been related to better 
performance under stress [46], and DHEAS may also protect against excessive increases in circulating cortisol levels under stress situations [47]. Most previous studies on the association between DHEAS and cognition have utilized cognitive tasks with significant time pressure $[6,44]$ that can have a stressful impact on performance, whereas we used Raven's CPM without time limit. Measuring DHEA, DHEAS, and cortisol simultaneously could provide more information on the associations of DHEAS with cognition [44].

Our study is in accordance with Azurmendi et al. who found no association of A4 or testosterone with cognition in prepubertal children [45]. On the other hand, testosterone concentrations have been associated with cerebral development, the findings being different in prepubertal girls and postpubertal boys, suggesting that CNS effects of androgens are sex-, time-, and also dose-spesific [48].

There was no difference in the Raven`s CPM score between children with clinical signs of adrenarche and children without them in the present study. In accordance with our finding, there was no difference in cognition between children with early adrenarche, defined by levels of DHEA and testosterone in saliva, and children with later adrenarche in one previous study [49] or in another study on girls with premature and on-time pubarche [15]. Nevertheless, girls with premature adrenarche have been observed to have better attention but poorer performance in verbal, working memory, and visuospatial tasks than girls with adrenarche on-time [50].

A strength of the present study is the relatively large population sample of girls and boys. We also had the opportunity to take parental education into account in the analyses. Although we used a welldefined method to measure cognition, a more comprehensive testing of different components of cognitive functions would have provided more information on the associations of DHEAS and IGF-1 with different aspects of cognition. The study had a cross-sectional design that does not allow us to make conclusions about causality of the relationships. Earlier results have been based on DHEA rather than DHEAS. DHEA is generally taken to be the active form of the hormone, but it has been indicated that DHEA levels in brain are influenced by peripheral levels of both DHEA and DHEAS [51]. 
Simultaneous measurement of cortisol could have provided more information on the role of stress in the associations of DHEAS and IGF-1 with cognition. Neither did we measure insulin-like growth binding proteins (IGFBP), which can either inhibit or enhance the binding of IGF-1 to its receptor [36].

The results of the present study suggest that higher serum IGF-1 is related to better cognition among prepubertal boys. We could not provide evidence for the associations of DHEAS or clinical signs of adrenarche with cognition in prepubertal children.

\section{Statements}

\subsection{Acknowledgements}

We thank the children and their parents who participated in this study and Ms Leila Antikainen for biochemical analyses. We are also grateful to the members of the PANIC team for their skillful contribution in performing the study.

\subsection{Ethics Statement}

The study protocol was approved by the Research Ethics Committee of the Hospital District of Northern Savo. All children participating in the study and their parents gave their informed written consent. All experiments on human participants were conducted with the Declaration of Helsinki.

\subsection{Disclosure statement}

The authors have no conflicts of interest to disclose.

\subsection{Funding Sources}

This work was supported by grants from Ministry of Social Affairs and Health of Finland, Ministry of Education and Culture of Finland, Finnish Innovation Fund Sitra, Social Insurance Institution of Finland, Finnish Cultural Foundation, Juho Vainio Foundation, Foundation for Pediatric Research, Paulo 
Foundation, Paavo Nurmi Foundation, Diabetes Research Foundation, Yrjö Jahnsson Foundation, Finnish Foundation for Cardiovascular Research, Research Committee of Kuopio University Hospital Catchment Area (State Research Funding) and Kuopio University Hospital (EVO funding number 5031343), Finnish Medical Foundation, Päivikki and Sakari Sohlberg Foundation, Rauha and Jalmari Ahokas Foundation, and the city of Kuopio. The funding sources had no role in the design and conduct of the study; collection, management, analysis, and interpretation of the data; preparation, review, or approval of the manuscript; and decision to submit the manuscript for publication.

\subsection{Author Contributions}

Aino Mäntyselkä: data curation, formal analysis, investigation, methodology, validation, visualization, writing the original draft, and reviewing and editing. Eero Haapala: data curation, methodology, validation, and reviewing and editing. Virpi Lindi: data curation, funding acquisition, methodology, supervision, validation, visualization, reviewing and editing, and project administration. Merja R. Häkkinen: data curation, investigation, methodology, validation and reviewing and editing. Seppo Auriola: data curation, investigation, methodology, validation and reviewing and editing. Jarmo Jääskeläinen: methodology, funding acquisition, resources, supervision, validation, and reviewing and editing. Timo A. Lakka: funding acquisition, methodology, project administration, resources, software, supervision, validation, and reviewing and editing. 


\section{References}

1. Maninger N, Wolkowitz OM, Reus VI, Epel ES, Mellon SH. Neurobiological and neuropsychiatric effects of dehydroepiandrosterone (DHEA) and DHEA sulfate (DHEAS). Front Neuroendocrinol. 2009 Jan;30(1):65-91.

2. Dong Y, Zheng P. Dehydroepiandrosterone sulphate: Action and mechanism in the brain. J Neuroendocrinol. 2012 Jan;24(1):215-24.

3. Greaves R, Wudy SA, Badoer E, Zacharin M, Hirst JJ, Quinn T, et al. A tale of two steroids: the importance of the androgens DHEA and DHEAS for early neurodevelopment. J Steroid Biochem Mol Biol. 2018 Apr;188:77-85.

4. Davis SR, Shah SM, McKenzie DP, Kulkarni J, Davison SL, Bell R.J. Dehydroepiandrosterone sulfate levels are associated with more favorable cognitive function in women. J Clin Endocrinol Metab. 2008 Mar;93(3):801-8.

5. de Menezes KJ, Peixoto C, Nardi AE, Carta MG, Machado S, Veras AB. Dehydroepiandrosterone, its sulfate and cognitive functions. Clin Pract Epidemiol Ment Health. 2016 Apr;29;12:24-37.

6. Alhaj HA, Massey AE, McAllister-Williams RH. Effects of DHEA administration on episodic memory, cortisol and mood in healthy young men: A double-blind, placebo-controlled study. Psychopharmacology (Berl). 2006 Nov;188(4):541-51.

7. Hunt PJ, Gurnell EM, Huppert FA, Richards C, Prevost AT, Wass JA, et al. Improvement in mood and fatigue after dehydroepiandrosterone replacement in addison's disease in a randomized, double blind trial. J Clin Endocrinol Metab. 2000 Dec;85(12):4650-6.

8. Gurnell EM, Hunt PJ, Curran SE, Conway C, Pullenayegum EM, Huppert FA, et al. Long-term DHEA replacement in primary adrenal insufficiency: A randomized, controlled trial. J Clin Endocrinol Metab. 2008 Feb;93(2):400-9.

9. Utriainen P, Laakso S, Liimatta J, Jääskeläinen J, Voutilainen R. Premature adrenarche -- a common condition with variable presentation. Horm Res Paediatr. 2015 May;83(4):221-31.

10. Caviness VS Jr, Kennedy DN, Richelme C, Rademacher J, Filipek PA. The human brain age 7-11 years: A volumetric analysis based on magnetic resonance images. Cereb Cortex. 1996 Sep-Oct;6(5):726-36.

11. Gogtay N, Giedd JN, Lusk L, Hayashi KM, Greenstein D, Vaituzis AC, et al. Dynamic mapping of human cortical development during childhood through early adulthood. Proc Natl Acad Sci. U S A. 2004 May;25;101(21):8174-9. 
12. Shaw P, Kabani NJ, Lerch JP, Eckstrand K, Lenroot R., Gogtay N, et al. Neurodevelopmental trajectories of the human cerebral cortex. J Neurosci. 2008 Apr;2;28(14):3586-94.

13. Nguyen TV, Gower P, Albaugh MD, Botteron KN, Hudziak JJ, Fonov VS, et al. The developmental relationship between DHEA and visual attention is mediated by structural plasticity of cortico-amygdalar networks. Psychoneuroendocrinology. 2016 Aug;70:122-33.

14. Nguyen TV, Wu M, Lew J, Albaugh MD, Botteron KN, Hudziak JJ, et al. Dehydroepiandrosterone impacts working memory by shaping cortico-hippocampal structural covariance during development. Psychoneuroendocrinology. 2017 Dec;86:110-121.

15. Sontag-Padilla LM, Dorn LD, Tissot A, Susman EJ, Beers SR, Rose SR. Executive functioning, cortisol reactivity, and symptons of psychopathology in girls with premature adrenarche. Dev Psychopathol. 2012 Feb;24(1):211-23.

16. Campbell BC. Adrenarche and middle childhood. Hum Nat. 2011 Sep;22(3):327-49.

17. Craig AD. How do you feel? Interoception: The sense of the physiological condition of the body. Nat Rev Neurosci. 2002 Aug;3(8):655-66.

18. Craig AD. How do you feel--now? The anterior insula and human awareness. Nat Rev Neurosci. 2009 Jan;10(1):59-70.

19. Miller WL. Androgen synthesis in adrenarche. Rev Endocr Metab Disord. 2009 Mar;10(1):3-17.

20. Silfen ME, Manibo AM, Ferin M, McMahon DJ, Levine LS, Oberfield SE. Elevated free IGF-I levels in prepubertal hispanic girls with premature adrenarche: Relationship with hyperandrogenism and insulin sensitivity. J Clin Endocrinol Metab. 2002 Jan;87(1):398-403.

21. Utriainen P, Voutilainen R, Jääskeläinen J. Girls with premature adrenarche have accelerated early childhood growth. J Pediatr. 2009 Jun;154(6):882-7.

22. I'Allemand D, Penhoat A, Lebrethon MC, Ardèvol R, Baehr V, Oelkers W, et al. Insulin-like growth factors enhance steroidogenic enzyme and corticotropin receptor messenger ribonucleic acid levels and corticotropin steroidogenic responsiveness in cultured human adrenocortical cells. J Clin Endocrinol Metab. 1996 Nov;81(11):3892-7.

23. Werner H, LeRoith D. Insulin and insulin-like growth factor receptors in the brain: Physiological and pathological aspects. Eur Neuropsychopharmacol. 2014 Dec;24(12):1947-53. 
24. Gunnell D, Miller LL, Rogers I, Holly JM, ALSPAC Study Team. Association of insulin-like growth factor I and insulin-like growth factor-binding protein-3 with intelligence quotient among 8- to 9-year-old children in the Avon longitudinal study of parents and children. Pediatrics. 2005 Nov;116(5):e681-6.

25. Carro E, Torres-Aleman I. Serum insulin-like growth factor I in brain function. Keio J Med. 2006 Jun;55(2):59-63.

26. Eloranta AM, Lindi V, Schwab U, Kiiskinen S, Kalinkin M, Lakka HM, et al. Dietary factors and their associations with socioeconomic background in Finnish girls and boys 6-8 years of age: The PANIC study. Eur J Clin Nutr. 2011 Nov;65(11):1211-8.

27. Raven J, Raven J, Court J. Coloured progressive matrices. manual for Raven`s progressive matrices and vocabulary scales. London: Oxford psychologist press Ltd; 1998.

28. Diamond A. Executive Functions. Annu Rev Psychol. 2013 Jul;64:135-168.

29. Saari A, Sankilampi U, Hannila ML, Kiviniemi V, Kesseli K, Dunkel L. New Finnish growth references for children and adolescents aged 0 to 20 years: Length/height-for-age, weight-for-length/height, and body mass index-for-age. Ann Med. 2011 May;43(3):235-48.

30. Tanner J. Growth at adolescence.2nd ed. Oxford UK:Blackwell scientific; 1962.

31. Häkkinen MR, Heinosalo T, Saarinen N, Linnanen T, Voutilainen R, Lakka T, et al. Analysis by LC-MS/MS of endogenous steroids from human serum, plasma, endometrium and endometriotic tissue. J Pharm Biomed Anal. 2018 Apr;152:165-72.

32. Rosenfield RL. Clinical review: Identifying children at risk for polycystic ovary syndrome. J Clin Endocrinol Metab. 2007 Mar;92(3):787-96.

33. van Pareren YK, Duivenvoorden HJ, Slijper FS, Koot HM, Hokken-Koelega AC. Intelligence and psychosocial functioning during long-term growth hormone therapy in children born small for gestational age. J Clin Endocrinol Metab. 2004 Nov;89(11):5295-302.

34. D'Ercole AJ, Ye P, Calikoglu AS, Gutierrez-Ospina G. The role of the insulin-like growth factors in the central nervous system. Mol Neurobiol. 1996 Dec;13(3):227-55.

35. Riikonen R. Treatment of autistic spectrum disorder with insulin-like growth factors. Eur J Paediatr Neurol. 2016 Nov;20(6):816-823. 
36. Åberg ND, Brywe KG, Isgaard J. Aspects of growth hormone and insulin-like growth factor-I related to neuroprotection, regeneration, and functional plasticity in the adult brain. ScientificWorldJournal. 2006 Jan;18;6:53-80.

37. Cotman CW, Berchtold NC. Exercise: A behavioral intervention to enhance brain health and plasticity. Trends Neurosci. 2002 Jun;25(6):295-301.

38. Cotman CW, Berchtold NC, Christie LA. Exercise builds brain health: Key roles of growth factor cascades and inflammation. Trends Neurosci. 2007 Sep;30(9):464-72.

39. Juraska JM, Willing J. Pubertal onset as a critical transition for neural development and cognition. Brain Res. 2017 Jan;1;1654(Pt B):87-94.

40. Wierenga LM, Bos MGN, Schreuders E, Vd Kamp F, Peper JS, Tamnes CK, et al. Unraveling age, puberty and testosterone effects on subcortical brain development across adolescence. Psychoneuroendocrinology. 2018 May;91:105114.

41. Patton GC, Viner R. Pubertal transitions in health. Lancet. 2007 Mar;31;369(9567):1130-9.

42. Veldhuis JD, Metzger DL, Martha PM Jr, Mauras N, Kerrigan JR, Keenan B, et al. Estrogen and testosterone, but not a nonaromatizable androgen, direct network integration of the hypothalamo-somatotrope (growth hormone)-insulin-like growth factor I axis in the human: Evidence from pubertal pathophysiology and sex-steroid hormone replacement. J Clin Endocrinol Metab. 1997 Oct;82(10):3414-20.

43. Chaler EA, Meazza C, Guercio G, Maceiras M, Rivarola MA, Laarej K, et al. Serum IGF-I and IGFBP-3 reference values from a chemiluminescent assay in normal children and adolescents of hispanic and italian origin: Presence of sexual dimorphism in IGF-I values. J Pediatr Endocrinol Metab. 2009 Dec;22(12):1127-35.

44. do Vale S, Selinger L, Martin Martins J, Gomes AC, Bicho M, do Carmo I, et al. The relationship between dehydroepiandrosterone (DHEA), working memory and distraction--a behavioral and electrophysiological approach. PLoS One. 2014 Aug;8;9(8):e104869. DOI:10.1371/0104869.

45. Azurmendi A, Braza F, Sorozabal A, García A, Braza P, Carreras MR, et al. Cognitive abilities, androgen levels, and body mass index in 5-year-old children. Horm Behav. 2005 Aug;48(2):187-95. 
46. Russo SJ, Murrough JW, Han MH, Charney DS, Nestler EJ. Neurobiology of resilience. Nat Neurosci. 2012 Nov;15(11):1475-84.

47. do Vale S, Martin Martins J, Fagundes MJ, do Carmo I. Plasma dehydroepiandrosterone-sulphate is related to personality and stress response. Neuro Endocrinol Lett. 2011 Aug;32(4):442-8.

48. Nguyen TV. Developmental effects of androgens in the human brain. Journal of Neuroendocrinology. 2018 Feb;30(2):1 13.

49. Klauser P, Whittle S, Simmons JG, Byrne ML, Mundy LK, Patton GC, et al. Reduced frontal white matter volume in children with early onset of adrenarche. Psychoneuroendocrinology. 2015 Feb;52:111-8.

50. Tissot A, Dorn LD, Rotenstein D, Rose SR, Sontag-Padilla LM, Jillard CL, et al. Neuropsychological functioning in girls with premature adrenarche. J Int Neuropsychol Soc. 2012 Jan;18(1):151-6.

51. Kancheva R, Hill M, Novák Z, Chrastina L, Kancheva L, Stárka L. Neuroavtive steroids in periphery and cerebrospinal fluid. Neuroscience. 2011 Sep; 191:22-7.

52. Sankilampi U, Hannila ML, Saari A, Gissler M, Dunkel L. New population-based references for birth weight, length, and head circumference in singletons and twins from 23 to 43 gestation weeks. Ann Med. 2013 Sep;45(5-6):446-54. 
